\title{
Comparative Study on the Nutritional Value of Pidan and Salted Duck Egg
}

\author{
P. Ganesan*, T. Kaewmanee ${ }^{1}$, S. Benjakul ${ }^{2}$, and B. S. Baharin \\ Department of Food Technology, Universiti Putra Malaysia, Selangor, Serdang 43400, Malaysia \\ ${ }^{1}$ Department of Food Science and Nutrition, Faculty of Science and Technology, \\ Prince of Songkla University, Muang, Pattani 94000, Thailand \\ ${ }^{2}$ Department of Food Technology, Faculty of Agro-Industry Prince of Songkla University, \\ Hat Yai, Songkhla 90112, Thailand
}

\begin{abstract}
Pidan and salted duck eggs are of nutritional rich alternative duck egg products which are predominantly consumed in China, Thailand, South Korea and other Chinese migrated countries. Both eggs are rich in proteins, lipids, unsaturated fatty acids and minerals. A Pidan whole egg contains $13.1 \%$ of protein, $10.7 \%$ of fat, $2.25 \%$ of carbohydrate and $2.3 \%$ of ash, whereas the salted duck egg contains $14 \%$ of protein, $16.6 \%$ of fat, $4.1 \%$ of carbohydrate and $7.5 \%$ of ash. The fresh duck egg contains a range of $9.30-11.80 \%$ of protein, $11.40-13.52 \%$ of fat, $1.50-1.74 \%$ of sugar and $1.10-1.17 \%$ of ash. Proteins, lipids, and ash contents are found to be greatly enhanced during the pickling and salting process of pidan and salted duck eggs. However, the alkaline induced aggregation of pidan leads to degradation and subsequent generation of free peptides and amino acids. Very few amino acids are found to be lost during the pickling and storage. However, no such losses of amino acids are reported in salted duck eggs during the salting process of $14 \mathrm{~d}$. Phospholipids and cholesterol contents are lower in pidan oil and salted duck egg yolk oil. Thus, the pidan and salted duck eggs are nutritionally rich alternatives of duck egg products which will benefit the human health during consumption.
\end{abstract}

Key words: pidan, salted duck egg, nutritional value, amino acid

\section{Introduction}

Duck eggs consumption either as fresh or preserved accounts for about $30 \%$ among the total egg consumption in the countries like China and South East Asia (Pingle, 2009). Preserved egg products includes pidan and salted duck eggs are one of the least expensive duck egg products which are widely consumed in most of the South East Asian countries such as, Thailand, Malaysia, Singapore and East Asian countries like China and South Korea (Ganesan and Benjakul, 2010a, 2010b; Ganesan and Benjakul, 2011a, 2011b, 2011c; Ganesan and Benjakul, 2013; Kaewmanee et al., 2009a, 2009b; Kaewmanee et al., 2011a, 2011b; Kaewmanee et al., 2012; Su and Lin, 1994). Most of these products are typically made with the duck eggs due the characteristics flavor and

*Corresponding author: P. Ganesan, Department of Food Technology, Universiti Putra Malaysia, Serdang 43400, Selangor, Malaysia. Tel: 60-3-8946-8412, Fax: 60-3-8942-3552, E-mail: palanivel@upm.edu.my aroma raised form the yolk of the duck egg (Ganesan and Benjakul, 2011a, 2011b; Kaewmanee et al., 2009a, 2009b; $\mathrm{Li}$ and Hsieh, 2004). Traditionally, pidan are made by coating the eggs in the mixture of pickling paste includes ash, clay, lime and salt (He et al., 1995) or by soaking in pickling solution containing $4.2 \% \mathrm{NaOH}, 5 \% \mathrm{NaCl}$ and $2 \%$ Chinese tea for several weeks to months based on the method of pickling (Chen and Su, 2004; Wang and Fung, 1996). Salted duck egg is made by brining the duck egg in the saturated saline solution or by coating the egg with soil paste mixed with salt (Lai et al., 1999).

Typical characteristics of both eggs differs, pidan white developed gel when alkali penetrates into egg white during the pickling and yolk becomes dark green color, whereas salted duck egg white becomes more watery and yolk becomes hardened during salting process (Ganesan and Benjakul 2011a, 2011b; Kaewmanee et al., 2009a, 2009b). Both pidan and salted duck can be consumed after pickling along with the rice congee. However, salted duck egg needs to be heated by pan frying or boiling before consumption. Salted duck egg white proteins 
undergo gelation during the heat treatments and results in the coarser aggregation of the proteins (Kaewmanee et al., 2009a, 2009b). Alkaline induced gelation of pidan results in the amber brown pidan white gel mainly due to the Maillard reaction of pidan white.

During processing and the making of the pidan and salted duck egg, alters the composition of both eggs. Certain nutritional value of both eggs was found to be increased and certain was found to losed during the process and storage. Pidan and salted duck egg are found to be an extensive source of protein and amino acids but the protein content is found to be decreased in pidan, whereas it found to be increased in slated duck egg during the storage process (Ganesan and Benjakul 2011a, 2011b; Kaewmanee et al., 2009a, 2009b). However, mineral content of both eggs is found to be extensively increased during the storage periods (Ganesan and Benjakul 2013; Kaewmanee et al., 2009a, 2009b). Therefore, this review is focused on comparative study of the nutrition composition of pidan and salted duck egg.

\section{Pidan and salted duck egg production-current tech- nologies}

Pidan and salted duck eggs are traditionally produced in China, Thailand, Malaysia, Singapore and South Korea for many centuries (Ganesan et al., 2013; Kaewmanee et al., 2009a, 2009b; Li and Lai, 1978; Lin 1983; Liu et al., 2005; Wu, 1992; Yang and Chen, 2001) and are shown in Fig. 1. A traditional method of producing these eggs varies with season, time and temperature and its long process. To overcome the time limitation and faster production of these eggs many novel techniques have developed. The basic principle is involved in the pidan formation is about alkaline induced aggregation of pidan white and yolk during pickling of eggs. In contrast salted duck egg, develop salted watery egg white and harden orange

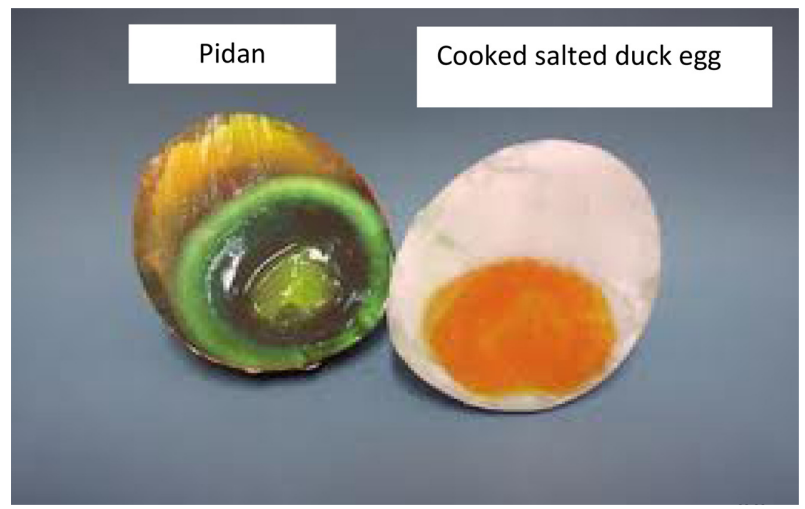

Fig. 1. Image of pidan and cooked salted duck egg. colored egg yolk during salting. Recently, Ganesan and Benjakul (2010a, 2010b) produce pidan with 3 wk soaking of duck eggs in pickling solution contains $4.2 \%$ $\mathrm{NaOH}, 5 \% \mathrm{NaCl}$ and $2 \%$ Chinese tea and different cations. Further to reduce time they pretreated the duck egg with $5 \%$ acetic acid and found that they enhanced pickling components such as $\mathrm{NaOH}$, Chinese tea and cations in pidan (Ganesan and Benjakul, 2011a, 2011b). Similarly salted duck egg also developed with the duck egg pretreated with $0.1 \mathrm{~N} \mathrm{HCl}$ (Lai et al., 1999). However, inorganic solvent is not recommended in food. To overcome the above problem, Kaewmanee et al. (2011a, 2011b) produced the salted duck egg of comparable hardening ratio to traditional salted duck egg with the duck egg pretreated with $5 \%$ acetic acid for $30 \mathrm{~min}$, followed by immersing in $0.25 \%(\mathrm{w} / \mathrm{v})$ neutrase for $90 \mathrm{~min}$.

\section{Nutritive value of pidan and salted duck egg}

Pidan, and salted duck egg are a rich source of protein, lipids, and minerals (Table 1). Water is the major constituent in whole duck egg which ranged between $62.90 \%$ to $71.77 \%$ (data not show in Table 1), proteins are found to be higher in egg white solids, whereas lipids and proteins are found to be the major constituents in yolk. Minerals are also found in egg white and yolk. Pidan whole egg contains $13.1 \%$ of protein, $10.7 \%$ of fat, $2.25 \%$ of carbohydrate and $2.3 \%$ of ash, whereas salted duck egg contains $14 \%$ of protein, $16.6 \%$ of fat, $4.1 \%$ of carbohydrate and $7.5 \%$ of ash and the fresh duck egg contains in the range of $9.30-11.80 \%$ of protein, $11.40-13.52 \%$ of fat, $1.50-1.74 \%$ of sugar and $1.10-1.17 \%$ of ash. In case of salted duck egg, the marked increased in salted duck content was found in egg white up to about 0.9 and $7 \%$ during salting for $2 \mathrm{wk}$ for the yolk and white, respectively. Thus, pickling and salting technologies greatly alters the nutritive value of both pidan and salted duck whole egg (Table 1).

\section{Proteins and amino acids in pidan white and salted duck egg white}

Proteins as a major constituent in the egg white proteins are found to be decreased during pidan pickling process of $3 \mathrm{wk}$ and the salted duck egg salting process of $2 \mathrm{wk}$. Alkaline pickling results in the migration of alkali in the egg white which results in subsequent degradation and aggregation of the pidan white egg protein. Similarly salting also causes some effects in the salted duck egg white protein and its losses its viscous nature and become more watery due to the increase water content from the yolk 
Table 1. Nutritive composition of fresh duck egg, pidan and salted duck egg

\begin{tabular}{|c|c|c|c|c|c|c|}
\hline \multirow{2}{*}{ Samples } & \multicolumn{5}{|c|}{ Compositions (\% wet wt. basis) } & \multirow{2}{*}{ Sources } \\
\hline & Protein & Fat & Carbohydrate & Ash & Salt & \\
\hline \multicolumn{7}{|l|}{ Fresh duck egg } \\
\hline Whole egg & $9.30-11.80$ & $11.40-13.52$ & $1.50-1.74$ & $1.10-1.17$ & 0.33 & $\begin{array}{l}\text { Kaewmanee } \text { et al. (2013) } \\
\text { Lai et al. (2010) }\end{array}$ \\
\hline Egg white & $8.60-10.50$ & $0.00-0.03$ & $1.01-3.5$ & $0.70-0.74$ & 0.39 & $\begin{array}{l}\text { Kaewmanee et al. (2013) } \\
\text { Lai et al. (2010) }\end{array}$ \\
\hline Egg yolk & $14.10-16.0$ & $35.80-37.25$ & $1.65-3.40$ & $0.59-2.20$ & 0.45 & $\begin{array}{c}\text { Kaewmanee et al. (2013) } \\
\text { Lai et al. }(2010) \\
\text { Chi and Tseng (1998) }\end{array}$ \\
\hline \multicolumn{7}{|l|}{ Pidan } \\
\hline Whole egg & 13.1 & 10.7 & 2.2 & 2.3 & NR & Ganesan and Benjakul (2013) \\
\hline \multicolumn{7}{|l|}{ Salted duck egg } \\
\hline Whole egg & 14 & 16.6 & 4.1 & 7.5 & NR & Kaewmanee et al. (2013) \\
\hline Egg white & $9.55-10.10$ & $0.03-0.05$ & $1.66-2.77$ & $3.02-4.04$ & $3.96-6.90$ & Kaewmanee et al. (2013) \\
\hline Egg yolk & $16.70-21.30^{\mathrm{a}}$ & $38.39-53.71$ & $2.49-4.06$ & $1.91-2.45$ & $0.54-0.87$ & Kaewmanee et al. (2013) \\
\hline
\end{tabular}

$\mathrm{NR}=$ No Reported.

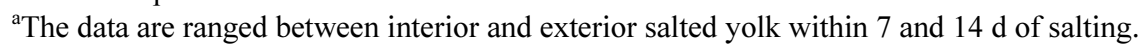

during salting, the high salt content in egg white induce the water migration from egg yolk. In Pidan, alkaline pickling causes the extend degradation of protein and formation of the lysinioalanine (LAL), maillard ractions and racemaization process (Liardon and Hurrel, 1983; Ganesan and Benjakul, 2010a, 2010b, 2011a, 2011b). Loss of the lysine and other racemaized amino acids leads to the subsequent loss of protein in pidan. However, it can be prevented by adding amino acids or cations in the pickling solution during the making process of pidan (Chang et al., 1999a; Chang et al., 1999b). The alkaline process results in subsequent changes in amino acid contents in pidan and leads to both increase or decrease in the levels amino acids (Chang et al., 1999c). Leucine, aspargine, and glutamine are of those amino acids that are synthesized during pidan making, whereas lysine, serine, and threonine were subsequently lossed during the making process of pidan (Table 2). However, it depends on the ions involved the making process of the pidan. In salted duck egg there was no report regarding the amino acid contents of salted duck egg white during the various salting process.

\section{Protein content of pidan and salted duck egg yolk}

Yolk proteins are of complex of lipids and proteins and exist as lipoproteins which are commonly called as low density lipoproteins (LDL) or high density lipoproteins (HDL). Alkaline induced aggregation of the yolk proteins cause the maximum degradation of yolk proteins that leads to many peptides and amino acids production in the yolk. Leucine, aspargine and glutamine are of those amino acids which found higher in the pidan yolk during extensive alka-
Table 2. Amino acid contents of white and yolk of fresh egg and pidan (expressed as residues/1000 residues)

\begin{tabular}{ccccc}
\hline \multirow{2}{*}{ Amino acids } & \multicolumn{2}{c}{ White } & \multicolumn{2}{c}{ Yolk } \\
\cline { 2 - 5 } & Fresh & Pidan-Zn & Fresh & Pidan-Zn \\
\hline Aspartic acid/Asparagine & 91 & 91 & 89 & 93 \\
Threonine* & 67 & 65 & 60 & 63 \\
Serine & 97 & 90 & 99 & 86 \\
Glutamic acid/Glutamine & 123 & 124 & 110 & 114 \\
Glycine & 61 & 62 & 54 & 59 \\
Alanine & 68 & 70 & 77 & 78 \\
Cysteine & 1 & 2 & 4 & 4 \\
Valine* & 70 & 74 & 64 & 67 \\
Methionine* & 54 & 55 & 26 & 30 \\
Isoleucine* & 41 & 44 & 50 & 49 \\
Leucine* & 81 & 83 & 86 & 88 \\
Tyrosine & 33 & 33 & 34 & 35 \\
Phenylalanine* & 58 & 59 & 36 & 39 \\
Hydroxylysine & 0 & 16 & 0 & 12 \\
Lysine* & 61 & 42 & 70 & 58 \\
Histidine* & 17 & 21 & 37 & 29 \\
Arginine & 6 & 5 & 5 & 6 \\
Tryptophan* & 33 & 24 & 52 & 45 \\
Hydroxyproline & 0 & 0 & 0 & 0 \\
Proline & 37 & 40 & 45 & 47 \\
\hline
\end{tabular}

a Pidan- $\mathrm{Zn}: \mathrm{ZnCl}_{2}$ treated pidan.

*Essential amino acid.

line pickling (and also some other essential amino acid (Table 2 and 3)). In other hand some amino acids such as lysine is found to be lower during pickling (Ganesan and Benjakul, 2010a, 2010b). However, salted duck egg yolk protein does not undergo any changes during salting period of 7 to $14 \mathrm{~d}$ (Kaewmanee et al., 2009a, 2009b). 
Table 3. Amino acid contents of white and yolk of fresh and salted duck egg (g/100g)

\begin{tabular}{|c|c|c|c|c|c|}
\hline Amino acids & Egg white & Egg yolk & Salted whole egg & Salted yolk & $\overline{\text { FAO/WHO (1991) }}$ \\
\hline Alanine & 7.04 & 8.36 & 6.07 & 7.19 & \\
\hline Arginine & 6.48 & 10.99 & 7 & 9.99 & \\
\hline Aspartic acid & 12.2 & 15.5 & 11.13 & 13.69 & \\
\hline Cysteine & 2.87 & 2.64 & 2.4 & 2.51 & \\
\hline Glutamic acid & 15.5 & 19.7 & 14.17 & 17.74 & \\
\hline Glycine & 4.13 & 4.88 & 3.63 & 4.32 & \\
\hline Histidine* & 2.9 & 4.16 & 2.73 & 3.63 & 1.9 \\
\hline Isoleucine* & 6.61 & 8.66 & 5.6 & 7.08 & 2.8 \\
\hline Leucine* & 10.16 & 13.99 & 9.4 & 12.3 & 6.6 \\
\hline Lysine* & 8.06 & 12.17 & 7.93 & 11.11 & 5.8 \\
\hline Methionine* & 3.99 & 3.78 & 3.03 & 3.47 & \\
\hline Phenylalanine* & 6.86 & 6.81 & 5.77 & 5.98 & \\
\hline Proline & 4.35 & 6.46 & 4.2 & 5.85 & \\
\hline Serine & 7.98 & 13.26 & 8.5 & 11.96 & \\
\hline Threonine* & 4.49 & 6.87 & 4.83 & 7.44 & 3.4 \\
\hline Tryptophan* & 1.25 & 1.77 & 2.26 & 1.64 & 1.1 \\
\hline Tyrosine & 4.57 & 6.78 & 4.63 & 6.23 & \\
\hline Valine* & 8.09 & 9.49 & 6.73 & 7.8 & 3.5 \\
\hline Methionine+Cystine & 6.86 & 6.42 & 5.43 & 5.98 & 2.5 \\
\hline Phenylalanine + Tyrosine & 11.43 & 13.59 & 10.4 & 17.98 & 6.3 \\
\hline Total essential amino acids & 52.41 & 67.7 & 48.28 & 60.45 & 33.9 \\
\hline
\end{tabular}

*Essential amino acid.

Table 4. Mineral composition of fresh, pidan and salted duck egg

\begin{tabular}{|c|c|c|c|c|c|}
\hline \multirow{2}{*}{ Parameters } & \multicolumn{2}{|c|}{ White (mg/100g) } & \multicolumn{3}{|c|}{ Yolk (mg/100g) } \\
\hline & Fresh & Pidan- $\mathrm{Zn}^{\mathrm{a}}$ & Fresh & Pidan-Zn & Salted duck egg \\
\hline $\mathrm{Ca}$ & 23.12 & 29.2 & 158.22 & 307.84 & 114 \\
\hline $\mathrm{Mg}$ & 79.89 & 28.89 & 18.23 & 25.22 & 10 \\
\hline $\mathrm{Na}$ & 754 & 2250.9 & 72.3 & 1516.81 & 3780 \\
\hline K & 604.4 & 748.6 & 131.42 & 246.67 & 116.74 \\
\hline $\mathrm{Zn}$ & NR & 2.63 & 3.95 & 3.75 & 2.83 \\
\hline $\mathrm{Cu}$ & 0.79 & 0.35 & 0.14 & 0.34 & 0.1 \\
\hline $\mathrm{Fe}$ & 1.11 & 2.19 & 8.51 & 6.63 & 3.75 \\
\hline $\mathrm{N}$ & 12.86 & 12.68 & 4.91 & 5.32 & NR \\
\hline $\mathrm{S}$ & 1.7 & 1.17 & 0.28 & 0.29 & NR \\
\hline
\end{tabular}

aPidan- $\mathrm{Zn}: \mathrm{ZnCl}_{2}$ treated pidan.

$\mathrm{NR}=$ Not reported.

\section{Mineral content of pidan and salted duck egg white and yolk}

Minerals are of the excellent source in both pidan and salted duck egg white and yolk (Table 4). This in turns depends on the type of methods or minerals used in the pickling or salting process of making pidan or salted duck egg. Potassium and sodium are the major minerals in egg white. Lead or zinc is found only in the pidan pickled with lead or zinc. Sodium is found extensively increased in both pidan and salted duck egg white. However, the salt content in yolk of both egg is found to lowered due to higher lipid content and aggregation or gelation of yolk lipid impedes ion salt (Chi and Tseng, 1998; Ganesan and Benjakul, 2011a, 2011b; Kaewmanee et al., 2009a, 2009b).
This show the minerals are migrated during the pickling process of pidan or during the salting process of salted duck egg. Decrease in the mineral contentis most likely due to the diluting effect during pickling or salting process of the eggs. Sulphur content was found to be greatly reduced during the pickling process of pidan was most likely due to the loss of sulphur during alkaline process. No such loss of other minerals was reported in salted duck egg white during the salting process.

\section{Lipid and fatty acid composition of pidan and salted duck yolk}

The pickling and salting process greatly influenced the lipid and fatty acid contents of pidan and salted duck egg 
Table 5. Lipid compositions of Pidan and salted duck egg yolk

\begin{tabular}{|c|c|c|c|c|c|}
\hline \multirow[b]{2}{*}{ Compositions } & \multicolumn{2}{|c|}{ Fresh } & \multicolumn{2}{|c|}{ Salted duck } & \multirow{2}{*}{$\begin{array}{c}\text { Pidan } \\
\text { Liu et al } \\
(2005)\end{array}$} \\
\hline & $\begin{array}{l}\text { Liu et al. } \\
(2005)\end{array}$ & $\begin{array}{c}\text { Kaewmanee et al. } \\
\text { (2009) }\end{array}$ & $\begin{array}{l}\text { Liu et al. } \\
\text { (2005) }\end{array}$ & $\begin{array}{c}\text { Kaewmanee et al. } \\
\text { (2009) }\end{array}$ & \\
\hline Lipid content (\%) & 38.21 & 37.25 & 45.21 & $38.39-53.71^{\mathrm{a}}$ & 26.65 \\
\hline \multicolumn{6}{|l|}{ Yolk oil (mg/g) } \\
\hline Triacylglycerols & NR & 591 & NR & $561-581$ & NR \\
\hline Diacylglycerols & NR & 9.5 & NR & $8.3-9.5$ & NR \\
\hline Phospholipids & 350.5 & 399 & 233.5 & $410-430$ & 175.1 \\
\hline Cholesterol & 38.15 & NR & 37.51 & NR & 28.51 \\
\hline \multicolumn{6}{|l|}{ Fatty acids (\%) } \\
\hline $16: 00$ & 24.86 & 27.2 & 27.86 & $26.8-27.5$ & 25.65 \\
\hline $16: 01$ & 5.59 & 2.25 & 2.11 & $2.24-2.66$ & 2.36 \\
\hline $18: 00$ & 7.94 & 6.19 & 6.93 & $5.50-5.63$ & 6.66 \\
\hline 18:01 & 42.39 & 47.5 & 44.06 & $48.00-48.40$ & 45.2 \\
\hline $18: 02$ & 14.85 & 8.08 & 14.93 & $6.88-8.73$ & 15.41 \\
\hline $20: 04$ & 1.83 & 2.62 & 1.36 & $2.57-2.79$ & 2.73 \\
\hline $22: 06$ & 1.47 & 1.66 & 1.79 & $1.61-1.95$ & 1.09 \\
\hline Others & 1.07 & NR & 0.12 & NR & 0.3 \\
\hline
\end{tabular}

$\mathrm{NR}=$ Not reported.

${ }^{a}$ The data are ranged between lipid composition of interior and exterior salted yolk within 7 and $14 \mathrm{~d}$ of salting.

yolk (Table 5). Lower lipid content is found in pidan yolk mostly due to the saponification of yolk lipids during alkaline pickling. In contrast, higher lipid content is found in the salted duck egg yolk, this is most likely due to the high salt content leads to driving out of moisture from egg yolk. Lipid from the yolk contained triacylglycerol and phospholipids as the major constituent while diacylglycerol was found at low content. Phospholipids and cholesterol contents of pidan yolk were found to be lower than salted duck egg yolk. Salted duck egg yolk oil contains $233 \mathrm{mg}$ of phospholipids and $37 \mathrm{mg}$ of cholesterol which is comparatively lower than fresh egg yolk oils. Kaewmanee et al. (2009a, 2009b) reported that free fatty acid was not found in salted duck egg yolks. Oleic, palmitic and linoleic acids are the most abundant fatty acids are found in both pidan and salted duck egg yolk (Kaewmanee et al., 2009a, 2009b; Liu et al., 2005). From the report of Kaewmanee et al. (2009a, 2009b), fatty acid profile of salted duck egg lipid was similar with that of fresh yolk lipid and salting generally had no impact on fatty acid composition of yolk lipids. On the nutritive fact of the lipids in both pidan and salted duck egg, they will serve as an alternative low cholesterol egg products, which also rich in other essential food lipids.

\section{Conclusion}

Pidan and salted duck eggs are rich in protein, amino acids, lipids, essential fatty acids and minerals. Pidan undergoes alkaline degradation of proteins which leads to the generation of many functional peptides and amino acids to the certain amount. Further extensive degradation is prevented by the cations in the pickling solutions leads to healthy alternative egg product. However, during salting process, salted duck egg white becomes more watery and yolk is bright orange red color. Thus both pidan and salted duck egg are nutritive rich alternative egg products and consumption at moderate level benefits the health.

\section{References}

1. Chang, H. M., Tsai, C. F., and Li, C. F. (1999a) Inhibition of lysinoalanine formation in alkali-pickled duck egg (Pidan). Food Res. Int. 32, 559-563.

2. Chang, H. M., Tsai, C. F., and Li, C. F. (1999b) Quantification of racemization of amino acids in alkali-treated duck eggs by micellar capillary electrophoresis. J. Agric. Food Chem. 47, 479-484.

3. Chang, H. M., Tsai, C. R. and Li, C. F. (1999c) Changes in amino acid composition and lysinoalanine during formation in alkali-pickled duck eggs. J. Agric. Food Chem. 47, 14951500.

4. Chen, J. W. and Su, H. P. (2004) A new process for preparing spots-free pidan. J. Chin. Anim. Sci. 33, 79-88.

5. Chi, S. P. and Tseng, K. H. (1998) Physicochemical properties of salted pickled yolk from duck and chicken eggs. $J$. Food Sci. 33, 507-513.

6. Ganasen, P. and Benjakul, S. (2010a) Chemical compositions and properties of alkali pickled egg (Pidan) as affected by cations and selected pickling ingredients. Ph.D. Thesis. Prince of Songkla University, Hat Yai, Thailand. 
7. Ganasen, P. and Benjakul, S. (2010 b) Physical properties and microstructure of pidan yolk as affected by different divalent and monovalent cations. LWT-Food Sci. Technol. 43, 77-85.

8. Ganasen, P. and Benjakul, S. (2011a) Effect of three cations on the stability and microstructure of protein aggregate from duck egg white under alkaline condition. Food Sci. Technol. 17, 343-349.

9. Ganasen, P. and Benjakul, S. (2011b) Chemical compositions, physical properties and microstructure of pidan white as affected by different divalent and monovalent cations. J. Food Biochem. 35, 1528-1537.

10. Ganasen, P. and Benjakul, S. (2011c) Effects of green tea and Chinese tea on the composition and physical properties of pidan white. J. Food Proc. Preserv. 35, 907-916.

11. Ganasen, P. and Benjakul, S. (2013) Effect of different cations on pidan composition and flavor in comparison to the fresh duck egg. Korean. J. Food Sci. An. 33, 214-220.

12. He, T. J., Gao, K. Y., and Yan, Z. Y. (1994) The study about sodium hydroxide substitutes sodium carbonate to produce pidan. Food Ind. Sci. 3, 13.

13. Kaewmanee, T., Benjakul, S., and Visessanguan, W. (2009a) Effect of salting processes on chemical composition, textural properties and microstructure of duck egg. J. Sci. Food Agric. 89, 625-633.

14. Kaewmanee, T., Benjakul, S., and Visessanguan, W. (2009b) Changes in chemical composition, physical properties and microstructure of duck egg as influenced by salting. Food Chem. 112, 560-569.

15. Kaewmanee, T., Benjakul, S., and Visessanguan, W. (2011a) Effect of $\mathrm{NaCl}$ on thermal aggregation of egg white proteins from duck egg. Food Chem. 125, 706-712.

16. Kaewmanee, T., Benjakul, S., and Visessanguan, W. (2011b) Effects of salting processes and time on the chemical composition, textural properties, and microstructure of cooked duck egg. J. Food Sci. 76, S139-S147.

17. Kaewmanee, T., Benjakul, S., and Visessanguan, W. (2012)
Effect of acetic acid and commercial protease pretreatment on salting and characteristics of salted duck egg. Food Bioprocess Tech. 5, 1502-1510.

18. Lai, K. M., Chi, S. P., and Ko, W. C. (1999) Change in yolk states of duck egg during long-term brining. J. Agric. Food Chem. 4, 733-736.

19. Li, C. W. and Lai, C. Y. (1978) Studies on the proteolytic properties of the alkaline duck egg white. J. Chinese Agric. Chem. Soc. 16, 24.

20. Li, J. and Hsieh, Y. P. (2004) Traditional Chinese food technology and cuisine. Asia Pacic J. Clin. Nutr. 13, 147-155.

21. Liardon, R. and Hurrel, R. F. (1983) Amino acid racemization in heated and alkali-treated proteins. J. Agric. Food Chem. 31, 432-437.

22. Lin, C. W. (1983) The storage of egg. In: The chemistry and utility of egg. pp. 98-121. Hua Shiang Yuan Publishing Co., Taipei.

23. Liu, L. Y., Yang, M. H., Lin, J. H., and Lee, M. H. (2005) Lipid profile and oxidative stability of commercial egg products. J. Food Drug Anal. 13, 78-83.

24. Pingle, H. (2009). Waterfowl production for food security. Paper presented at the Proceedings of the IV World Waterfowl Conference 2009, Thrissur, India. pp. 5-15.

25. Su, H. P. and Lin, C. W. (1993) A new process for preparing transparent alkalized egg and its quality. J. Sci. Food Agric. 61, 117.

26. Wang, J. and Fung, D. Y. C. (1996) Alkaline-fermented foods: A review with emphasis on pidan fermentation. Crit. Rev. Microbiol. 22, 101-138.

27. Wu, Q. L. (1992) New Technology used in protection of pidan2,3,4-oxy-Ca-benzoate acid. J. Food Sci. 7, 32.

28. Yang, S. C. and Chen, K. H. (2001) The oxidation of cholesterol in the yolk of selective traditional Chinese egg products. Poultry Sci. 80, 370-375.

(Received 2013.10.14/Revised 2014.1.7/Accepted 2014.1.29) 